\title{
Native high-resolution 3D SSFP MR angiography for assessing the thoracic aorta
}

\author{
Florian von Knobelsdorff ${ }^{1,2^{*}}$, Henriette Gruettner ${ }^{1,2}$, Ralf F Trauzeddel ${ }^{1,2}$, Andreas Greiser ${ }^{3}$, \\ Jeanette Schulz-Menger ${ }^{1,2}$ \\ From 17th Annual SCMR Scientific Sessions \\ New Orleans, LA, USA. 16-19 January 2014
}

\section{Background}

To omit risks of contrast agent administration, native magnetic resonance angiography (MRA) is desired for assessing the thoracic aorta. Aim was to evaluate a native steady-state free-precession (SSFP) 3D MRA in comparison to contrast-enhanced MRA as the gold standard.

\section{Methods}

Seventy-six prospective patients with known or suspicion of thoracic aortic disease underwent MRA at $1.5 \mathrm{~T}$ using i) native 3D SSFP MRA with ECG and navigator gating and high isotropic spatial resolution $(1.3 \times 1.3 \times 1.3 \mathrm{~mm}$ 3 ) and ii) conventional contrast-enhanced ECG-gated gradient echo 3D MRA $(1.3 \times 0.8 \times 1.8 \mathrm{~mm} \mathrm{3})$. Datasets were compared at 9 aortic levels regarding image quality (score 0-3: 0 = poor, $3=$ excellent) and aortic diameters, as well as observer dependency and final diagnosis.

\section{Results}

Native 3D-MRA was acquired successfully in 70/76 subjects (mean acquisition time $8.6 \pm 2.7 \mathrm{~min}$ ), while irregular breathing excluded 6/76 subjects. Aortic diameters agreed close between both methods at all aortic levels $(\mathrm{r}=0.99$; bias $\pm \mathrm{SD}-0.12 \pm 1.2 \mathrm{~mm})$ with low intra- and inter-observer dependency (intraclass correlation coefficient 0.99). Native MRA studies resulted in the same final diagnosis as the contrast-enhanced MRA. Mean image quality score was superior with native compared to contrast-enhanced MRA $(2.4 \pm 0.6$ vs. $1.6 \pm 0.5 ; \mathrm{p}<0.001)$. The Figure provides a set of examples acquired with both techniques (left: native, right: contrast-enhanced).

\section{Conclusions}

Accuracy of aortic size measurements, certainty in defining the diagnosis and benefits in image quality at the aortic root underscore the use of the tested high-resolution
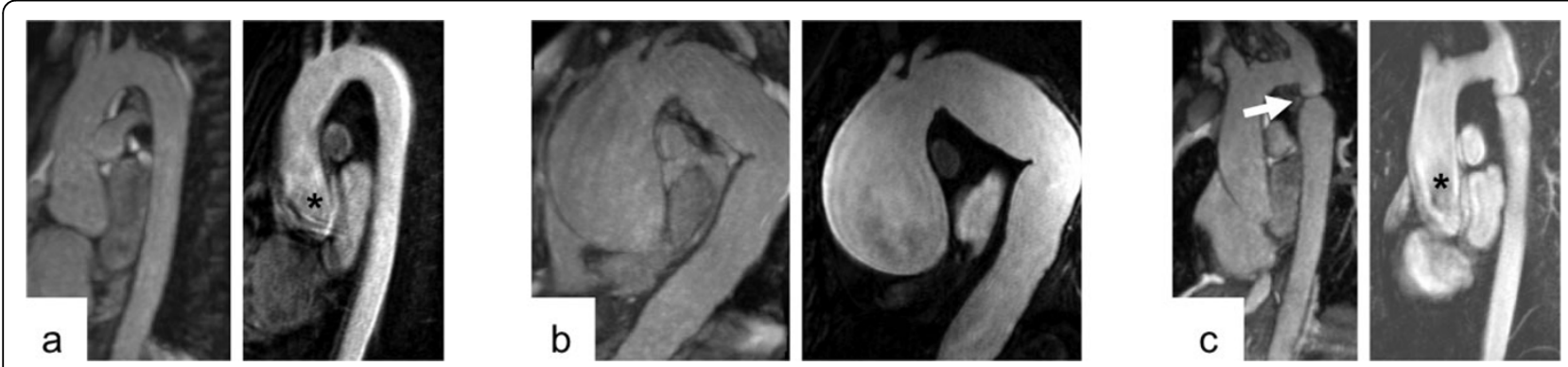

Figure 1 Set of examples of the native MRA (left) and the contrast-enhanced MRA (right): a) Thoracic aorta with normal dimensions. The sharpness of the aortic root achieved with the native MRA (left) is visible in comparison to the blurry borders provided by the contrast-enhanced MRA (*; right). b) Large ascending aortic aneurysm. c) Aortic coarctation (white arrow). Again the blurry aortic root with the contrast-enhanced MRA is recognizable (*; right).

${ }^{1}$ Cardiac MRI, Charité Medical Faculty, Berlin, Germany

Full list of author information is available at the end of the article 
native 3D SSFP MRA as an appropriate alternative to contrast-enhanced MRA to assess the thoracic aorta.

\section{Funding}

None.

\section{Authors' details}

${ }^{1}$ Cardiac MRI, Charité Medical Faculty, Berlin, Germany. ${ }^{2}$ Cardiology and Nephrology, HELIOS Clinics, Berlin, Germany. ${ }^{3}$ Siemens Healthcare, Erlangen, Germany.

Published: 16 January 2014

doi:10.1186/1532-429X-16-S1-P165

Cite this article as: von Knobelsdorff et al: Native high-resolution 3D

SSFP MR angiography for assessing the thoracic aorta. Journal of

Cardiovascular Magnetic Resonance 2014 16(Suppl 1):P165.

Submit your next manuscript to BioMed Central and take full advantage of:

- Convenient online submission

- Thorough peer review

- No space constraints or color figure charges

- Immediate publication on acceptance

- Inclusion in PubMed, CAS, Scopus and Google Scholar

- Research which is freely available for redistribution

Submit your manuscript at www.biomedcentral.com/submit
C Biomed Central 